\title{
Diet and State of Nutrition of Pakistani Infants in Bradford, Yorkshire
}

\author{
W. R. AYKROYD,* M.D., SC.D. ; M. A. HOSSAIN,* M.B., B.S., DIP.NUTR.LOND.
}

Brit. med. F., 1967, 1, 42-45

The presence in the United Kingdom of considerable numbers of immigrants from tropical countries, mainly the West Indies, Pakistan, and India, is a new phenomenon. It is of interest and importance to learn how these are adapting themselves to their new environment. In this paper some observations on Pakistani immigrant families are reported, concerned chiefly with dietary practices. There is little as yet in the literature about Pakistani immigrants; they have received much less attention than the West Indians, a larger group more in the public eye than immigrants from Asia.

The observations were made in Bradford, Yorkshire, where there is now a colony of some 13,000 Asians, mostly Pakistani. The inquiry originated in a letter to the Department of Human Nutrition, in July 1965, from Dr. W. D. Dolton, Deputy Medical Officer, Health Department, Bradford, who suspected that the health of infants and young children in the immigrant families might be adversely affected by poor nutrition (Dolton, 1965). After discussions in London and Bradford it was decided that the Department of Human Nutrition, in association with the Bradford Health Department, should study the following: (1) the feeding of Pakistani infants during the first year of life, (2) the weight gains of Pakistani infants, (3) morbidity and mortality in Pakistani infants, and (4) the dietary habits of Pakistani immigrants in general.

One of us (M. A. H., who comes from East Pakistan and graduated at Dacca University) spent four months in Bradford from October 1965. He was given working accommodation and facilities by the Health Department, and had access to its records. Living in close contact with the Pakistani community, he collected information in infant welfare clinics and visited families in their homes to interrogate mothers and make direct observations of feeding practices.

\section{Immigrant Population}

The Pakistani men are mainly employed in the woollen mills, where they earn good wages of the order of $£ 15$ a week, ten or more times as much as they would earn at home. The majority are in the age group 20-40. The men usually arrive in Bradford without their wives ; living as cheaply as possible, they save money for a few years to bring their wives and any children born in Pakistan to England. The women, on joining their husbands, pass suddenly from a rural or semirural environment in Pakistan to that of a British industrial town. Most know no English. While the Moslem purdah system is weakening in Pakistan, it still influences marital relations and the place of women in the family. The women do not remain in purdah in England, but they occupy a somewhat "withdrawn" position in the community in accordance with Moslem tradition. For this reason, and because of their lack of English, \footnotetext{
- Department of Human Nutrition, London School of Hygiene and
Tropical Medicine.
}

they do not seek work, and are fully occupied in looking after their husbands, children, and homes. In Bradford they are ready to make use of the excellent maternal and child health services. Most infants come under medical and public health supervision, being usually brought to the infant welfare clinics when they are under 3 weeks of age. Nearly all the Pakistani infants are delivered in maternity hospitals.

\section{Infant-feeding}

Preliminary inquiries at welfare clinics gave a broad picture of infant-feeding practices. We were told that, as a result of the instruction and supervision provided by the clinics and health personnel, the immigrant mothers had adopted an "artificial " infant-feeding reginen similar to that of English infants in Bradford. To supplement this general account of feeding practices, 100 Pakistani mothers with children under 18 months of age were interviewed by M. A. H. Most of these had been resident in England for less than two years, and nearly all the babies were the first born to the mothers after joining their husbands. Their ages at the time of interview are given in Table $\mathrm{I}$.

TABLE I.-Age of 100 Babies when Their Mothers were Interviewed

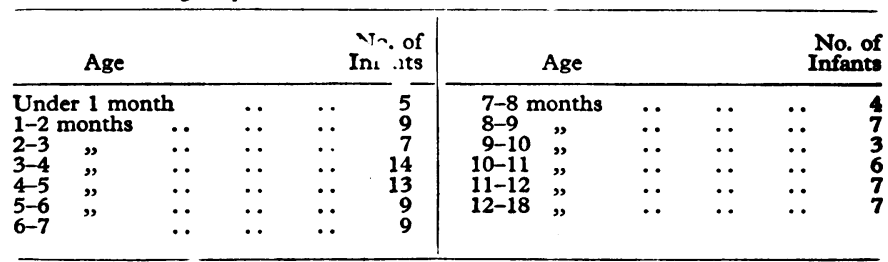

The interrogations covered the duration of breast-feeding, the reasons for its cessation, the foods given to replace breast milk and the time of their introduction, and the hygienic aspects of artificial feeding. M. A. H. talked with mothers and fathers in Urdu, and was assisted in his contacts with families by a Pakistani health visitor and a Pakistani liaison officer in the Health Department. Families were cooperative and ready to answer questions.

\section{Duration of Breast-feeding}

Eleven infants were still receiving breast milk at the time of the interview. Five of these, of whom three were under 3 weeks of age and the other two aged 2 to $3 \frac{1}{2}$ months, were getting breast milk only. The remaining six, receiving some breast milk in addition to other foods, were between 2 and $3 \frac{1}{2}$ months of age.

The breast-feeding history of the remaining 89 , no longer breast-fed, is shown in Table II. 
Forty-four mothers said they left off breast-feeding abruptly and 25 said the process was "gradual"; these figures do not include the infants "never breast-fed," nor of course those still on the breast.

TABLE II.-Time of Abandonment of Breast-feeding (89 Infants)

\begin{tabular}{|c|c|c|c|c|c|c|c|c|c|c|}
\hline \multicolumn{4}{|l|}{ Time } & $\frac{\text { No. }}{19}$ & \multicolumn{3}{|c|}{ Time } & \multicolumn{3}{|c|}{ No } \\
\hline $\begin{array}{l}\text { From birth ( } \\
0-1 \text { week } \\
1-2 \text { weeks } \\
2-3 \text { " } \\
3-4 \text { " } \\
1-2 \text { months }\end{array}$ & $\begin{array}{l}0 \text { br } \\
\therefore \\
\therefore \\
\therefore\end{array}$ & $\begin{array}{l}\mathrm{mi} \\
\because \\
\because \\
\therefore\end{array}$ & $\begin{array}{l}\text { all) } \\
\because \\
\because \\
\because \\
\therefore\end{array}$ & $\begin{array}{r}19 \\
17 \\
17 \\
9 \\
7 \\
11\end{array}$ & $\begin{array}{l}2-3 \\
3-4 \\
4-5 \\
5-6 \\
6-9 \\
9-12\end{array}$ & $\begin{array}{l}\text { Ionths } \\
\text { " } \\
\text { " } \\
\text { " }\end{array}$ & $\begin{array}{l}\because \\
\because \\
\because \\
\therefore\end{array}$ & $\begin{array}{l}. \\
\because \\
\because \\
\therefore\end{array}$ & $\begin{array}{l}\ldots \\
\therefore \\
\cdots \\
\cdots\end{array}$ & $\begin{array}{l}3 \\
2 \\
0 \\
2 \\
1 \\
1\end{array}$ \\
\hline
\end{tabular}

The majority of babies were thus removed from the breast early in infancy, or were never breast-fed at all. The situation with respect to breast-feeding is very similar to that found in a study made in 1959-60 of the infant-feeding practices of British mothers in Nottingham (mainly working-class) (Newson and Newson, 1963). The picture is surprising. Had the women remained in Pakistan they would have breast-fed their infants for a year or longer, according to the normal and unquestioned custom of their home communities. An attempt was made to elucidate some of the reasons underlying this abrupt change. Local doctors and nurses ascribed the adoption of artificial feeding mainly to "fashion." Only four of the mothers, however, gave fashion as the reason for early weaning (or a reply which could be so interpreted). In fact they gave a considerable variety of reasons, relating both to themselves and to their infants, but mostly to themselves. Some 50 mothers stated that they stopped breast-feeding because their milk was " not sufficient" or " unsatisfactory," or that they were prevented from breast-feeding by illness. Only six said they were advised by a doctor or nurse to take the baby off the breast. Reasons relating to the baby included: "illness"; "crying when put to the breast"; "baby not sucking properly"; "vomiting after breast-feeding"; "baby not digesting breast milk"; "constipation" (eight babies). Of the babies who were never breast-fed six were premature, and hence no doubt put on an artificial feeding regimen immediately after birth in the maternity hospital.

The kinds of processed milk given to the 89 infants were as follows: Ostermilk, 42 infants ; Cow and Gate, 26 infants ; National dried milk, 13 infants; and fresh milk, 8 infants.

Orange juice or Delrosa, and cod-liver oil or Adexolin (more often the latter), were provided from about the fourth week onwards, sometimes earlier or later. A cereal preparation (chiefly Farex or Farlene) was usually introduced into the diet at 1 to 3 months of age. Eggs were given to approximately half of the infants from about the third month onwards, and fresh fruits, soups, and tinned baby-foods were included in the diet of a smaller proportion at various points after the third month.

An attempt was made to determine the quantities of milk solids received by the infants. Mothers were asked to state the number of "measures" of Ostermilk, Cow and Gate, and National dried milk given daily at various stages throughout infancy. In general they had a clear idea of what the infants had received or were receiving. The number of measures as stated was compared with those recommended on the container. In the case of Ostermilk the recommended quantity at birth is two and a half "level measures" for each of five daily feeds, rising step by step to seven measures at 6 months. Each measure contains about $4.5 \mathrm{~g}$. of milk powder. The figures for 41 infants given Ostermilk can be summarized as follows: up to 3 months or thereabouts the infants were in general supplied with milk powder in excess of the recommended quantities, but from this point onward the majority received considerably less-that is, from 20 to 30 measures daily, as compared with the recommended 30 to 40 measures. There were similar trends for infants receiving Cow and Gate and National dried milk.
Some samples of reconstituted milk were taken from feedingbottles, and their content of milk solids was determined by the public analyst in the Health Department. The range of dilution was found to be considerable, but there was no general tendency to dilute the dried milk excessively.

The weight records (see Table III) suggest that the calorie needs of the Pakistani infants were satisfied. This means that the quantities of foods other than milk given to the infant would be in proportion to the milk intake-the less milk the more of these foods, and vice versa. The decrease in the amounts of milk given (relative to those recommended by the manufacturer) cannot have reduced intake of protein and other nutrients to any important extent. Farex, the most popular cereal preparation, contains $14 \%$ of protein and is fortified with calcium and riboflavine, nutrients of which milk is a good source; the usual quantities of Farex given daily from the fourth month onwards were two to four spoonfuls daily (say $12 \mathrm{~g}$.), these being added to the milk. Eggs were included in the diet of many of the infants. Sugar (about $22 \mathrm{~g}$. daily) was usually added to the feeds. Rough calculations show that in the circumstances protein requirements would be fully satisfied with an intake of 20 to 30 measures of milk powder daily ; intake would in fact be in the neighbourhood of $4 \mathrm{~g} . / \mathrm{kg}$. of body weight.

TABLE III.-Weights of English and Pakistani Infants (lb. and oz. to the

\begin{tabular}{|c|c|c|c|c|c|c|}
\hline & \multicolumn{3}{|c|}{ English Infants } & \multicolumn{3}{|c|}{ Pakistani Infants } \\
\hline & \multirow{2}{*}{$\begin{array}{c}\text { No. of } \\
\text { Weighings }\end{array}$} & \multicolumn{2}{|c|}{ Average Weight } & \multirow{2}{*}{$\begin{array}{l}\text { No. of } \\
\text { Weighings }\end{array}$} & \multicolumn{2}{|c|}{ Average Weight } \\
\hline & & lb. oz. & g. & & lb. oz. & g. \\
\hline 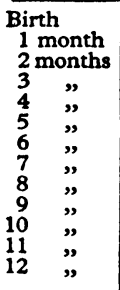 & $\begin{array}{r}205 \\
69 \\
74 \\
71 \\
81 \\
86 \\
78 \\
78 \\
74 \\
57 \\
52 \\
25 \\
71\end{array}$ & $\begin{array}{rr}7 & 3 \\
9 & 10 \\
11 & 5 \\
13 & 4 \\
14 & 15 \\
16 & 8 \\
17 & 8 \\
18 & 8 \\
19 & 10 \\
20 & 5 \\
20 & 7 \\
21 & 3 \\
21 & 13\end{array}$ & $\begin{array}{l}3,260 \\
4,365 \\
5,130 \\
6,010 \\
6,775 \\
7,485 \\
7,940 \\
8,390 \\
8,900 \\
9,215 \\
9,270 \\
9,610 \\
9,895\end{array}$ & $\begin{array}{r}219 \\
94 \\
119 \\
148 \\
124 \\
94 \\
92 \\
88 \\
91 \\
64 \\
49 \\
40 \\
42\end{array}$ & $\begin{array}{rr}6 & 9 \\
8 & 11 \\
10 & 12 \\
12 & 6 \\
14 & 0 \\
15 & 6 \\
16 & 8 \\
17 & 11 \\
18 & 9 \\
19 & 1 \\
20 & 3 \\
20 & 12 \\
21 & 4\end{array}$ & $\begin{array}{l}2,975 \\
3,940 \\
4,875 \\
5,615 \\
6,350 \\
6,975 \\
7,485 \\
8,025 \\
8,420 \\
8,645 \\
9,155 \\
9,410 \\
9,640\end{array}$ \\
\hline
\end{tabular}

One possible reason for giving less milk than the recommended amount might be economy, families being reluctant to buy more tins of milk per month for the growing infant, and perhaps feeling that the amounts given in the earlier months of life would suffice throughout infancy. We are convinced, however, that there was no deliberate restriction in the quantities offered to the infants, that they were offered all they could take, and that intake relative to recommended quantities fell off because these were in excess of requirements after mixed feeding was introduced. There may be a similar trend in the artificial feeding of English infants.

Apart from the feeding regimen it was important to discover whether the feeding-bottles were handled in a sanitary way by the Pakistani mothers. Inquiries elicited the following methods of cleaning bottles:

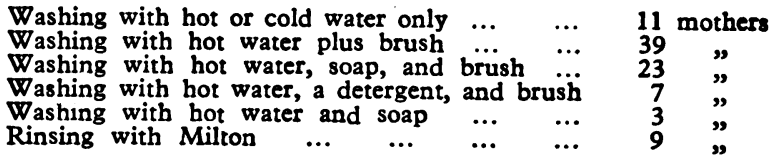

No comparison could be drawn between these bottle-cleaning practices and those of English mothers. Evidently, however, standards of cleanliness were reasonably good, which reflects the efficient teaching of the health services and the readiness of the mothers to learn.

\section{Weight in Infancy}

Records of the weights of English and Pakistani infants, at birth and at the various months during the first year of life, 
were available in the maternity hospitals and infant welfare clinics. These are presented in Table III, which shows the number of weighings at the different stages and the average figures for both groups. Many of the records relate of course to the same infants as they progressed through the first year. The monthly weighings were made when the infant was within a week, either way, of the age in question.

At birth the Pakistani infants were on the average about $10 \mathrm{oz}$. (285 g.) lighter than the English infants, a statistically significant difference. Throughout the rest of infancy the former remained a little behind the latter in average weight, but the difference at the age of 12 months was only $9 \mathrm{oz}$. $(255$ g.). The Pakistani infants were thus well developed at 12 months so far as weight is a criterion of development. Insufficient figures were available to extend the comparison beyond the first year.

\section{Infant Mortality}

Infant mortality data for non-Asian and Asian children in 1965 are shown in Table IV. The Asian group included a few Indian Children, but the great majority were Pakistani.

TABLE IV.-Infant Mortality in Bradford in 1965

\begin{tabular}{|c|c|c|c|c|c|}
\hline & & \multicolumn{2}{|c|}{ Non-Asian } & \multicolumn{2}{|c|}{ Asian } \\
\hline & & $\begin{array}{l}\text { Total } \\
\text { No. }\end{array}$ & $\underset{\text { Rate }}{\text { Mortality }}$ & $\begin{array}{l}\text { Total } \\
\text { No. }\end{array}$ & $\begin{array}{c}\text { Mortality } \\
\text { Rate }\end{array}$ \\
\hline $\begin{array}{l}\text { Live births } \\
\text { Deaths under } 1 \text { year (I.M.R.) } \\
\text { Neonatal deaths } \\
\text { Post-neonatal deaths } \quad .\end{array}$ & $\begin{array}{l}\cdots \\
\cdots \\
\cdots\end{array}$ & $\begin{array}{r}5,143 \\
117 \\
69 \\
48\end{array}$ & $\begin{array}{r}22 \cdot 7 \\
13 \cdot 4 \\
9 \cdot 3\end{array}$ & $\begin{array}{r}508 \\
24 \\
16 \\
8\end{array}$ & $\begin{array}{l}47 \cdot 2 \\
31 \cdot 5 \\
15 \cdot 7\end{array}$ \\
\hline
\end{tabular}

The infant mortality rate in Asian infants was twice that in non-Asian infants, itself above the national average. The difference is less marked when Asian children and non-Asian children of social classes IV and V are compared ; in the latter the rate was 30 . Neonatal and post-neonatal deaths both contributed to the excess of Asian deaths, the former somewhat more than the latter, as follows:

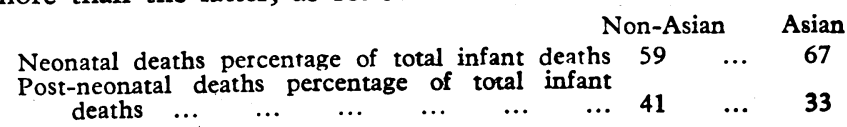

There is at present no evidence that the higher mortality in the Asian infants was associated with nutritional factors. In the post-neonatal period gastroenteritis was not an important cause of death in either group. The number of postneonatal deaths ascribed to pneumonia was much higher than the number ascribed to gastroenteritis, but proportionately pneumonia was a more frequent cause of death in the nonAsian than in the Asian group. It is unlikely that differences in parity-for example, the preponderance of first and second births in the Asian group, contributed to the difference in the mortality rate.

In many parts of the world there is an association between malnutrition and high mortality in the pre-school age group (1-4), particularly between 1 and 2 years of age. No unusual mortality has occurred in Asian children of this age group in Bradford ; actually only one death was recorded in 1965.

\section{Diet of Pakistan Families in Bradford}

Adult Pakistanis in Bradford live on "Pakistani" food. In 1965 in Bradford there were 63 Pakistani grocers and greengrocers, 13 butchers, and 28 "café-clubs" (Dolton, 1966). Visits were made to the premises of merchants importing foods for the Asian population; there a large assortment of foods characteristic of the Indian peninsula was to be seen-rice. atta, ghee, pulses, brinjals and other vegetables, and a multiplicity of spices-imported from various parts of the world. In most households the traditional whole-wheat (atta) chappaties are regularly made; a British company has put on the market a " chappati flour" to meet this special demand. In the circumstances such a diet is more expensive than an English workingclass diet-for example, ghee costs $1 \mathrm{~s}$. $6 \mathrm{~d}$. more a pound than butter. Nevertheless, there is little sign of "assimilation" so far as adult dietary practices are concerned; if anything the supply of Asian foods is increasing in amount and variety. The Pakistanis themselves say that English food is tasteless and unappetizing because of its lack of spices. It seems unlikely that their diet, based on a whole-wheat staple, is deficient in calories and nutrients. There is no shortage of money to spend on food.

\section{Discussion}

Seen in the light of the situation in the homeland, the abandonment of breast-feeding and the successful adoption of artificial feeding by Pakistani mothers immediately after arrival in England are facts of great interest. Little relevant information is available from Pakistan itself, but Gordon, Chitkara, and Wyon (1963) have made important studies in the Ludhiana district of the Punjab, which is in India but just across the border from Pakistan. The majority of Pakistani immigrants in Bradford come from areas in Pakistan adjacent to Ludhiana, and their environment before leaving home was probably similar to that in Ludhiana. The data obtained by Gordon and his colleagues were based on 775 infants observed in "longitudinal" studies covering the period from birth to 4 years. Most infants were given breast milk, in varying amounts, for a year or longer. In the group as a whole the infant mortality rate was 160 . Infants did not survive unless they were breast-fed ; 19 out of 20 artificially fed from birth died. The mortality rate in those breast-fed from birth, with the addition of supplementary foods at about the sixth month, was 120 . The main cause of mortality was a combination of gastroenteritis and malnutrition, which the authors called "weanling diarrhoea."

The relatively low infant mortality rate (43) in the Pakistani community in Bradford is thus a remarkable phenomenoneven though it is above current British rates. Under the tutelage of the health services the Pakistani mothers immediately adopted feeding practices sufficiently satisfactory from the standpoint of nutrition and sanitation to give their infants a much greater chance of survival than that of infants in Pakistan itself. But it is surprising that the mothers should have turned to an English artificial feeding regimen so readily, in view of the all-importance of breast-feeding in their native country.

Little significance can be attached to the reasons given by the mothers for discontinuing breast-feeding. The common reply that breast milk was insufficient cannot reflect physiological reality, there being no reason why healthy young women should not produce milk in abundance. It seems that the immigrants find themselves in a situation in which an artificial feeding regimen for infants is the accepted practice, taught and encouraged by the health services; moreover, it is "modern" and successful like other things in a developed country. While they readily adopt it, past tradition may prompt them to find excuses. The report of Newsom and Newsom (1963) shows that many English mothers in Nottingham gave similar reasons for abandoning breast-feeding. A comment of these authors is worth quoting:

"It is clear that a necessary precondition of any large-scale decline in breast-feeding is the availability and cheapness of suitable artificial or substitute foods, feeding-bottles, teats, and means of sterilization. With higher material standards of living, including running water, efficient sanitation, and a modern stove, it requires little effort to take the necessary hygienic precautions; and in a more affluent society the total cost of artificial feeding is no longer an important consideration. In an underdeveloped country alternatives to natural feeding are inconvenient and impracticable; with the material assets of civilization the inconveniences of bottle-feeding 
are so diminished as to be almost non-existent, and it is breastfeeding for which a positive effort has to be made."

Such amenities are available to the immigrants in Bradford. The ease with which infant-feeding preparations can be obtained is of importance ; as is usual in England, these are on sale at stalls in the infant welfare clinics. The sight of a young Pakistani mother, carrying her baby and speaking no English, cheerfully detaching a pound note from a wad of several pound notes to pay for tins of Glaxo or Farex at one of these stalls, makes it easier to appreciate her attitude towards breast-feeding.

It may be desirable to counter the tendency to give less milk, relative to the infant's needs, during the later stages of infancy. Given present poor (though improving) housing conditions, special emphasis should be laid on cleanliness in preparing foods for the infants. The situation should be carefully watched, since unexpected problems may arise. Enthusiasts for breastfeeding will deplore its abrupt abandonment by the immigrants, but clearly intensive educational efforts out of tune with the whole social situation would be required to encourage it. Since striking success has been achieved in preventing infant mortality there does not seem to be any need for radical changes in approach.

\section{Summary}

A study was made of the diet and state of nutrition of infants in Bradford, Yorkshire, belonging to a community of immigrants from Pakistan and born to mothers recently arrived in England. The men were receiving good wages. The inquiry was concerned with infant-feeding practices, weight gains during the first year of life, infant mortality, and the dietary habits of Pakistani immigrants in general.

Most of the Pakistani infants were removed from the breast within three weeks of birth and artificially fed according to current British methods. The reasons for the abandonment of breast-feeding were investigated by interviewing 100 mothers.
The basic reason seemed to be that artificial feeding was part of the new environment.

At birth the Pakistani infants were on the average about $10 \mathrm{oz}$. (280 g.) lighter than English infants in Bradford. Weight gains during the first year of life were, however, closely similar in the two groups.

The infant mortality rate in Asian infants (mainly Pakistani) was 47.2, as compared with 22.7 in non-Asian infants, the difference being mainly due to the greater number of neonatal deaths in the Asian group. In the part of Pakistan from which the immigrants come the infant mortality rate is perhaps of the order of 150.

The Pakistani auilt community in Bradford consumes a diet consisting almost entirely of the kind of foods to which they were accustomed at home.

Points of special interest were: (a) the prompt abandonment of breast-feeding in spite of the. fact that in the homeland a baby not breast-fed has little chance of survival; $(b)$ the successful adoption by Pakistani mothers of artificial feeding, under the tutelage of the local health services, within a short time of arrival in England; and $(c)$ the contrast between the retention of a Pakistani diet by the community in general and the immediate change to English infant-feeding practices.

We acknowledge gratefully the generous co-operation of Dr. John Douglas, Medical Officer of Health, Bradford ; Dr. W. D. Dolton, Deputy Medical Officer, Health Department; and the Health Committee of the City of Bradford.

\section{REFERENCES}

Dolton, W. D. (1965). 7. roy. Inst. publ. Hlth, 28, 265.

(1966). Roy. Soc. Hlth 7., 86, 22.

Gordon, J. E., Chitkara, I. D., and Wyon, J. B. (1963). Amer. 7. med. Sci., 245, 345.

Newson, J., and Newson, E. (1963). Patterns of Infant Care in an Urban Community. Pelican Books, Penguin, Harmondsworth, Middlesex.

\section{Medical New Year Honours}

The following names were included in the New Year Honours List published on 1 January.

\section{Barony for Life}

Sir Robert Platt, Bt., M.D., LL.D., M.Sc., F.R.C.P. Emeritus Professor of Medicine, University of Manchester. Born in 1900, Robert Platt qualified at Sheffield in 1921, where he took the M.D. in 1923. He held resident appointments in Sheffield and the Royal Northern Hospital, London, and obtained the M.R.C.P. in 1925. After holding several posts at the University and Royal Infirmary at Sheffield he became a physician at the Infirmary in 1934. During the second world war Platt served in the R.A.M.C., where he was officer-in-charge of the medical division of hospitals in Britain and overseas, and from 1944 Consulung Physician to the Southern Army in India, with the rank of Brigadier. In 1946 he was appointed to the chair of medicine at the University of Manchester, and in 1957 he was elected President of the Royal College of Physicians, an office he held until 1962. Sir Robert Platt has published numerous papers on medical genetics, hypertension and renal disease. He was chairman of the Joint Working Party on the Medical Staffing Structure in the Hospital Service, and of the committee set up by the Royal College of Physicians to examine the problem of smoking in relation to cancer of the lung and other diseases-whose reports were published in 1961 and 1962, respectively. In 1959 Professor Platt was created a baronet.

\section{K.B.E. (Civil Division)}

Max Lronard Rosenheim, C.B.E., M.D. President, Royal College of Physicians of London. Professor of Medicine, University of London. Born in 1908, Professor Rosenheim qualified from Cambridge and University College Hospital in 1932, obtaining the M.R.C.P. in 1934 and the M.D. in 1938. After resident appointments at his own hospital, he was appointed assistant medical registrar at Westminster Hospital, returning to U.C.H. in 1936. From 1941 to 1946 Professor Rosenheim served in the R.A.M.C., first as a medical specialist and then as Consulting Physician to the Allied Land Forces in S.E. Asia. In 1946 he became Deputy Director of the Medical Unit at
U.C.H., and was appointed to the Chair of Medicine there in 1950. His chief interests have been in the fields of renal disease and hypertension. In April 1966 Professor Rosenheim was elected President of the Royal College of Physicians.

\section{D.B.E. (Civil Division)}

Miss Albertine Louise Winner, O.B.E., M.D., F.R.C.P. Deputy Chief Medical Officer, Ministry of Health. Born in 1907, Dr. Winner qualified at U.C.H. in 1932, obtaining the M.D. in 1934 and the M.R.C.P. in 1935. After appointments at the Elizaheth Garrett Anderson Hospital and the Maida Vale Hospital for Nervous Diseases she was appointed a consultant physician at the former. During the second world war Dr. Winner served in the R.A.M.C., when she was Assistant DirectorGeneral of Army Medical Services with the rank of Lieutenant-Colonel, being awarded the O B.E. in 1947. In 1947 she joined the staff of the Ministry of Health, and in 1963 was aprointed Deputy Chief Medical Officer. In 1965 the title of Fellow of University College, London, was conferred on her. 